Article

\title{
Oxidative Potential Sensitivity to Metals, Br, P, S, and Se in PM10 Samples: New Insights from a Monitoring Campaign in Southeastern Italy
}

\author{
Salvatore Romano ${ }^{1, *}$ (C), Silvia Becagli ${ }^{2}$, Franco Lucarelli ${ }^{3}$, Mara Russo ${ }^{4}$ and \\ Maria Chiara Pietrogrande ${ }^{4}$ \\ 1 Department of Mathematics and Physics, University of Salento, 73100 Lecce, Italy \\ 2 Department of Chemistry, University of Florence, 50019 Sesto Fiorentino, Florence, Italy \\ Department of Physics, University of Florence, 50019 Sesto Fiorentino, Florence, Italy \\ 4 Department of Chemical and Pharmaceutical Sciences, University of Ferrara, 44121 Ferrara, Italy \\ * Correspondence: salvatore.romano@unisalento.it
}

Received: 15 March 2020; Accepted: 7 April 2020; Published: 9 April 2020

\begin{abstract}
Different analytical techniques were used in this work to investigate the relationships between oxidative potential (OP) and metal, Br, P, S, and Se concentration in PM10 samples. Dithiothreitol and ascorbic acid acellular assays were used to determine the oxidative potential (OP) in PM10 samples. The particle-induced X-ray emission technique was used to estimate the mass concentration of specific chemical elements. PM10 samples were collected in Lecce, a coastal site of the Central Mediterranean away from large sources of local pollution. Both winter and spring samples were analyzed to study the seasonal dependence of the relationships between OP values and chemical element concentrations. The Redundancy Discriminant Analysis (RDA) was applied to (volumeand mass-normalized) $\mathrm{OP}$ values as response variables and metal, $\mathrm{Br}, \mathrm{P}, \mathrm{S}$, and Se concentrations as explanatory variables. RDA triplots allowed to visualize the main relationships between PM10 OP values and corresponding chemical element concentrations. Spearman correlation coefficients were also used to investigate the relationships between $\mathrm{OP}$ values and metal, $\mathrm{Br}, \mathrm{P}, \mathrm{S}$, and Se concentrations, besides comparing RDA outcomes. The integrated approach based on two different techniques allowed to better highlight the potentially harmful effects associated with specific metals and other chemical elements in PM10 samples.
\end{abstract}

Keywords: PM chemical composition; air pollution; air quality observations; seasonal variations; oxidative potential; metals; redundancy discriminant analysis; Spearman correlation coefficient

\section{Introduction}

Particulate matter (PM) is a complex mixture of particles with different characteristics (e.g., mass, size, shape, surface area, solubility, acidity, and number) and different chemical components. Metals come from impurities derived from fuel additives and/or brakes and tires attrition, and they can be generally found adhered to PM particles [1,2]. Iron (Fe), nickel (Ni), vanadium (V), chromium (Cr), and copper $(\mathrm{Cu})$ are the most studied and analyzed transition metals due to their potential to produce reactive oxygen species (ROS) in biological systems [3]. $\mathrm{Fe}, \mathrm{Cu}, \mathrm{Ni}$, and $\mathrm{V}$ in fine $\mathrm{PM}$ have been found to be associated with cardiovascular and respiratory hospital admissions and mortality $[4,5]$, as well as increased heart rate and decreased lung function [6]. Heavy metals such as cadmium (Cd), lead $(\mathrm{Pb})$, and mercury $(\mathrm{Hg})$ are generally produced by industrial, combustion, extraction, and processing activities. They are also able to exert their toxic effects by the production of ROS [1]. These toxic effects are generally quantified by oxidative potential (OP), which is a measure of the capacity of PM to 
deplete certain antioxidant molecules such as ascorbic acid (AA) or dithiothreitol (DTT) in synthetic airway fluid and to generate ROS ([7,8] and references therein). OP has been proposed as a more relevant exposure metric that is closely related to biological responses to PM exposure compared to PM mass concentration $[9,10]$. In fact, oxidative stress is considered to be the main link between PM exposure and associated diseases [11-13]. PM OP was found to contribute to oxidative stress and inflammation in cultured human lung carcinoma cells [14]. Significant variations in PM OP levels were reported in the Netherlands and Belgium [15,16], London (UK) [17], Hungary [18], Chamonix (France) [19,20], and Canada [21,22]. Daher et al. [23] explained that the differences in the OP levels of PM samples are mostly related to transition metal content. In fact, the measurement of OP involves the redox activity of transition metals and organic chemicals, and it reflects interactions between different metals in the reaction [2].

In this study, two common acellular techniques based on low-cost spectrophotometric UV-Vis measurements, dithiothreitol ([24]) and ascorbic acid ([25]) assays were used to determine PM OP responses and study their relationships with metal, $\mathrm{Br}, \mathrm{P}, \mathrm{S}$, and Se mass concentrations. Several studies have been devoted to the analysis of the relationships between the main features of the PM OP values and specific metals ([23] and references therein). Liu et al. [22] performed an explanatory study in Toronto (Canada) and proved that the metal constituents in ambient PM may have partially contributed to the generation of OP and its adverse effects like systemic inflammation, oxidative stress, the perturbation of neural function, and physiological stress. Nishita-Hara et al. [26] carried out a continuous sampling of both fine and coarse PM particles in spring 2016 in Fukuoka (Japan) to study the effects of the main chemical components of Asian dust on PM OP. In particular, they investigated the contributions of both total and water-soluble metals to the OP determined by the DTT assay activity. They found a significant increase of OP during the analyzed Asian dust events, but the water-soluble transition metals were only responsible for $37 \%$ and $60 \%$ of the measured OP of the fine and coarse PM fraction, respectively. Saffari et al. [27] performed a year-long sampling campaign of quasi-ultrafine particles (with an aerodynamic diameter of less than $0.25 \mu \mathrm{m}$ ) at 10 distinct sites with different characteristics near Los Angeles (USA). They observed, particularly during winter, a strong correlation between DTT activity and transition metals $(\mathrm{Cr}, \mathrm{Mn}, \mathrm{V}, \mathrm{Fe}, \mathrm{Cu}, \mathrm{Cd}$, and $\mathrm{Zn})$ generally associated with the vehicular traffic source. Calas et al. [20] reported the main findings related to the seasonal OP variations from both the DTT and AA acellular assays, as well as their correlations with PM chemical composition over a one-year period in seven French urban background sites. They also found that correlation between volume-normalized OP and metal mass concentration was strongly seasonal-, assay-, and location-dependent.

Two previous works defined the main features of PM OP over Southeastern Italy at the same site of this study. First, Pietrogrande et al. [8] investigated the OP measured with both the AA and DTT assays in PM10 samples collected from December 2014 to October 2015 in order to highlight the sensitivity of both acellular methods. The seasonal dependence of the PM10 OP responses was also analyzed in relation to chemical composition and meteorological parameters. Then, Perrone et al. [28] simultaneously evaluated the OP responses of both PM10 and PM2.5 samples. They compared the DTT- and AA-OP responses to associate changes in the OP activity with particle size and the concentration of the redox-active species in PM10 and PM2.5 fractions. Being carried out at the center of the Mediterranean area, the main results of these last works could be considered representative of Mediterranean coastal sites away from large sources of local pollution [29]. With respect to the two previous works related to OP characterization over Southeastern Italy, this study is mainly related to the association of $\mathrm{OP}$ response sensitivity with several metal and $\mathrm{Br}, \mathrm{P}, \mathrm{S}$, and Se mass concentrations by using two different analytical techniques: the Redundancy Discriminant Analysis (RDA) and Spearman correlation coefficients. To the best of our knowledge, this study was the first to apply RDA to relate PM OP responses with specific metal and $\mathrm{Br}, \mathrm{P}, \mathrm{S}$, and Se mass concentrations. The RDA outcomes were compared with Spearman correlation coefficients to highlight benefits and limits of both used methodologies. The seasonal variations of the relationships between (volume- and mass-normalized) 
OP and chemical element concentration were also evaluated since the PM10 samples were collected both in winter and in spring.

\section{Experiments}

\subsection{Site Description and Sample Collection}

The measurements analyzed in this study were performed at the Aerosol and Climate Laboratory of the Mathematics and Physics Department of the Salento University in Lecce $\left(40.33^{\circ} \mathrm{N}, 18.11^{\circ} \mathrm{E}\right.$, $30 \mathrm{~m}$ a.s.l.) in Southeastern Italy. The monitoring site is located in a flat peninsular area, about $6 \mathrm{~km}$ away from the city center of Lecce, $20 \mathrm{~km}$ away from both the Ionian and Adriatic seas, and 100 and $800 \mathrm{~km}$ away from the Balkan and North African coasts, respectively. Therefore, the study site could be considered as representative of coastal sites of the Central Mediterranean, away from large sources of local pollution [30,31].

A low volume $\left(2.3 \mathrm{~m}^{3} \mathrm{~h}^{-1}\right)$ Hydra dual-sampler (FAI Instruments, Fonte Nuova, Rome, Italy) was used to simultaneously collect 72-h winter and 48-h spring PM10 samples on two different 47-mm-diameter filters. Polytetrafluoroethylene (PTFE) filters (TEFLO W/RING $2 \mu$ from VWR International, Radnor, Pennsylvania, USA) and quartz filters (Tissuquartz from PALLFLEX, Putnam, Connecticut, USA) were used to determine the chemical element mass concentrations and the OP responses, respectively. Both filters are characterized by an excellent aerosol collection efficiency [32]. Ten PM10 samples were collected, approximately once a week, both in winter (from January to March 2018) and in spring (from May to June 2018) to study the seasonal impact on the analyzed parameters. The PM10 mass concentrations of this study (Supplementary Table S1) were in reasonable agreement with previous data $[8,33]$ and, therefore, could be considered as representative of PM10 measurements at the study site.

\subsection{Chemical Element Mass Concentrations and Oxidative Potential Acellular Assays}

Metal (Al, As, Ba, Ca, Cd, Cr, Cu, Fe, K, Mn, Mo, Ni, Pb, Rb, Si, Sr, Ti, V, Zn, and Zr) and Br, $\mathrm{P}, \mathrm{S}$, and Se mass concentrations in each PM10 sample (Supplementary Table S1) were determined by the particle-induced X-ray emission (PIXE) technique at the INFN (Istituto Nazionale di Fisica Nucleare) LABEC (LAboratorio di tecniche nucleari applicate ai BEni Culturali) laboratory in Florence, Italy [34,35]. Each sample was irradiated with a $3.0 \mathrm{MeV}$ proton beam (10-150 nA intensity) for $90 \mathrm{~s}$. The beam was collimated to $\sim 2 \mathrm{~mm}^{2}$, and filter scanning was carried out to analyze most of the deposit area. Elemental concentrations were obtained by a calibration curve from a set of thin standards. Measurement accuracy was tested by the use of a NIST RM 8785 (National Institute of Standards and Technology, USA) standard. The minimum detection limits (MDLs) were of the order of few $\mathrm{ng} \mathrm{m}^{-3}$ for the low $\mathrm{Z}$ elements, down to a minimum value of $0.2 \mathrm{ng} \mathrm{m}^{-3}$ for $\mathrm{Cu}-\mathrm{Zn}$. The total uncertainties on elemental concentrations were determined by the sum of independent uncertainties on sample thickness $(5 \%)$, deposition area $(2 \%)$, air flow $(2 \%)$, and X-ray counting statistics $(2 \%-20 \%)$. The uncertainties increased when concentrations approached minimum detectable limits (MDLs). More details about the used methodology can be found in [34,35].

The oxidative potential responses of the collected PM10 samples were determined by the DTT and AA acellular assays (Supplementary Table S1). Both the assays were performed on $3 \mathrm{~mL}$ of the aqueous extract of a quarter of the sampled filters (extracted for $15 \mathrm{~min}$ in an ultrasonic bath using $10 \mathrm{~mL}$ of a $0.1 \mathrm{M}$ buffer at $\mathrm{pH}$ 7.4). The extract was filtered on a regenerate cellulose syringe filter $(13 \mathrm{~mm}$ and $0.22 \mu \mathrm{m}$, Kinesis) to remove the suspended solid particles, and then it was introduced into an amber vial at a constant temperature of $37^{\circ} \mathrm{C}$ using a dry bath. The OP response was evaluated as the antioxidant depletion rate of a known quantity of DTT and AA, according to the experimental procedure described in [8]. In more detail, both DTT and AA depletion rates were determined by linear fitting the reagent concentration as a function of time using five experimental points (at 5, 10, 15, 25, and $40 \mathrm{~min}$ ). A good linearity was, on average, found with correlation coefficient $R^{2} \geq 0.98$ [36]. Both DTT and AA depletion 
rates were also determined for blank quartz filters (Table S1) and subtracted from the response of each real PM10 sample in order to estimate the detection limits of the two used methods. The obtained $\mathrm{OP}$ values were then normalized to the total volume of sampled air, i.e., volume-normalized $\mathrm{OP}_{\mathrm{V}}$ (expressed in $\mathrm{nmol} \mathrm{min}^{-1} \mathrm{~m}^{-3}$ ), and to the PM10-sampled mass, i.e., mass-normalized $\mathrm{OP}_{\mathrm{m}}$ (expressed in $\mathrm{nmol} \mathrm{min}^{-1} \mu \mathrm{g}^{-1}$ ), as reported in Table S1. In particular, the volume-normalized $\mathrm{OP}_{\mathrm{V}}$ provides a measure of the atmospheric concentration of PM OP response, while the mass-normalized $\mathrm{OP}_{\mathrm{m}}$ represents a measure of the intrinsic OP of the overall PM10 contribution [8] (i.e., an indication of the PM10 "toxicity" in terms of $\mathrm{OP}$ ). Therefore, the $\mathrm{OP}_{\mathrm{V}}$ response is an extensive parameter depending on the PM10 mass concentration, as proven by $[8,28]$, while the intrinsic $\mathrm{OP}_{\mathrm{m}}$ can also provide insight on contributions of specific sources to the overall PM oxidative potential.

\subsection{Data Analysis}

The Redundancy Discriminant Analysis represents a widespread chemometric procedure to compare different types of data as chemical species or meteorological parameters [37,38]. The RDA could be considered as the multivariate extension of a simple linear regression applied to some sets of variables [39]. More specifically, the application of RDA needs the combination of two datasets: "species data" as response (or dependent) variables and "environmental variables" as explanatory (or predictive) variables [40]. In this work, the RDA technique was used to investigate the relationships between oxidative potential as "species data" and metal, Br, P, S, and Se mass concentrations as "environmental variables." The RDA analysis was applied to the selected datasets using the Fathom Toolbox for MATLAB [41]. In particular, the selected datasets were first standardized and then used as input (samples as rows and variables as columns) of the function $f_{-} r d a$ included in the Fathom Toolbox estimating all the statistical parameters needed for the RDA triplot. As described by [38], Monte Carlo tests were also used by setting 499 unrestricted permutations as input for the $f_{-} r d a$ function. Then, the structure of outputs from $f_{-} r d a$ function, the datasets of the transformed response variables, the weighted average scores, and a selected scaling factor (optimized to better visualize data) represented the inputs of the $f_{-} r d a P l o t$ function. This latter was used to plot two RDA outputs on the same graphical framework: the sample and the OP datasets represented the response variables in the first and in the second plot, respectively, while the chemical dataset represented the predictive variables in both plots. This overlap of two plots representing three variables (in this work, sample dataset as points, OP and chemical species dataset as arrows) is generally called an RDA triplot.

The regression analyses performed on the parameters used in this study were based on the non-parametric Spearman correlation coefficients, which are strictly related to rank and not dependent on data distribution. The thresholds of the $p$-value were $10 \%, 5 \%$, and $1 \%$ for the statistical tests (Supplementary Table S2).

\section{Results and Discussion}

The main features of the metal, Br, P, S, and Se mass concentrations and DTT and AA volume- and mass-normalized oxidative potential responses $\left(\mathrm{OP}_{\mathrm{V}}\right.$ and $\mathrm{OP}_{\mathrm{m}}$, respectively) were analyzed in this Section. RDA and Spearman correlation coefficients were the tools used to analyze major relationships between chemical element mass concentrations and oxidative potential responses. The changes of the relations between the winter and spring PM10 samples were also investigated.

\subsection{Metal, Br, $P, S$, and Se Mass Concentration Characterization}

Figure 1 shows the percentage mass concentrations of the analyzed chemical elements in winter and spring PM10 samples. Al, Ca, Fe, K, S, and Si were the most abundant elements in the analyzed samples. All the other chemical components were characterized by a not significant relative abundance of, in total, less than 3\%. In particular, among the analyzed chemical elements, S, Ca, and Si showed the highest relative abundance $(28 \%, 19 \%$, and $16 \%$, respectively, in winter and $35 \%, 21 \%$, and $18 \%$, respectively, in spring). According to [42], the most abundant chemical elements in this study (S, Ca, 
and $\mathrm{Si}$ ) can be associated with the "Agriculture Soil" and the "Natural Soil" sources characterized by respective abundancies larger than $1 \%$ in both sources (Table 1). Anthropogenic contributions were likely significant, since $\mathrm{Al}, \mathrm{Ca}, \mathrm{Fe}, \mathrm{K}, \mathrm{S}$, and $\mathrm{Si}$ can also be associated with the "Paved Road Dust," "Unpaved Road Dust," and "Construction" sources (Table 1). Road dust typically consists of particles deposited over the street pavement and resuspended into the atmosphere by passing vehicles [43]. Road dust represents one of the main components of anthropogenic coarse-mode PM [44], as also proven at the study site [29]. $\mathrm{Al}, \mathrm{Ca}, \mathrm{Fe}, \mathrm{K}, \mathrm{S}$, and $\mathrm{Si}$ can also be related to the "Motor Vehicle," "Coal-Fired Boiler," and "Oil Fired Power Plant" sources (Table 1), but with a lower percentage contribution, according to [42].

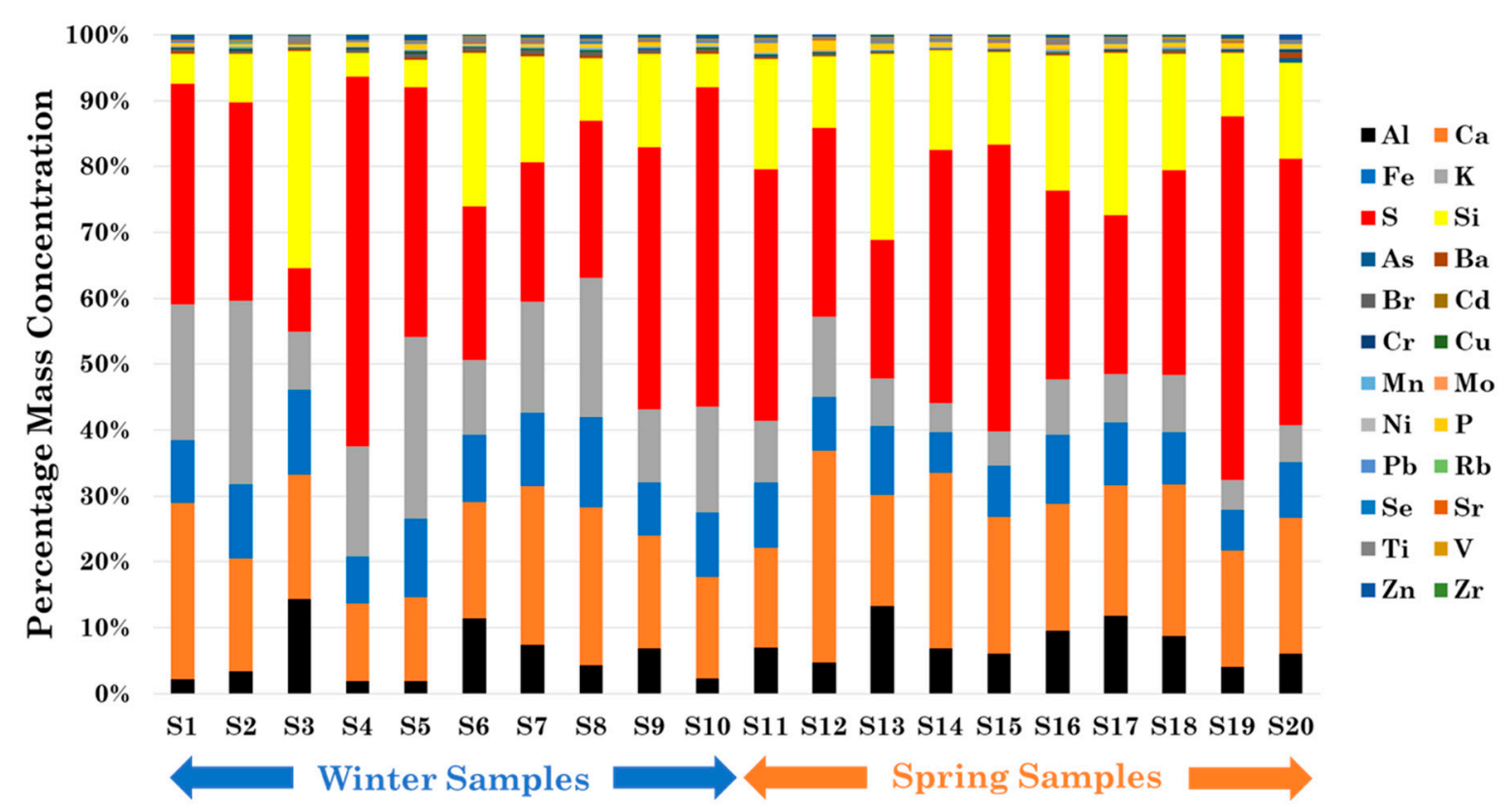

Figure 1. Bar plot of the mass concentration percentages of the investigated chemical elements in the 20 analyzed samples (S1-S10 in winter and S11-S20 in spring). The reported percentages are referred to the total sampled mass of all the 24 analyzed chemical elements.

Table 1. Clustering of the 20 PM10 samples analyzed in this study, according to Romano et al. [45]. Main pollution sources and corresponding chemical fingerprints (according to the Chow [42] classification) are also reported.

\begin{tabular}{cccc}
\hline Cluster & Samples & PM Sources & Chemical Fingerprints \\
\hline Anthropogenic & $\mathrm{S} 1, \mathrm{~S} 2, \mathrm{~S} 10$ & $\begin{array}{c}\text { Road Dust, Construction, } \\
\text { Motor Vehicle, } \\
\text { Coal-Fired Boiler, } \\
\text { Oil Fired Power Plant }\end{array}$ & $\mathrm{Al}, \mathrm{Ca}, \mathrm{Fe}, \mathrm{K}, \mathrm{Pb}, \mathrm{S}, \mathrm{Si}$ \\
\hline Heavy Rain & $\mathrm{S} 5, \mathrm{~S} 9, \mathrm{~S} 11, \mathrm{~S} 13$ & Natural Soil & $\mathrm{Al}, \mathrm{Ca}, \mathrm{Fe}, \mathrm{K}, \mathrm{Mg}, \mathrm{P}, \mathrm{S}, \mathrm{Si}, \mathrm{Ti}$ \\
\hline Desert Dust & $\mathrm{S} 3, \mathrm{~S} 6, \mathrm{~S} 12$ & Marine & $\mathrm{Al}, \mathrm{Ba}, \mathrm{Ca}, \mathrm{Cu}, \mathrm{Fe}, \mathrm{K}, \mathrm{Si}, \mathrm{Zn}$ \\
\hline Marine & $\mathrm{S} 4, \mathrm{~S} 7, \mathrm{~S} 8$ & $\begin{array}{c}\text { Natural Soil, } \\
\text { Agricultural Soil, } \\
\text { Vegetative Burning }\end{array}$ & $\mathrm{Al}, \mathrm{Ca}, \mathrm{Fe}, \mathrm{K}, \mathrm{Mg}, \mathrm{P}, \mathrm{S}, \mathrm{Si}, \mathrm{Ti}$ \\
\hline Late Spring & $\mathrm{S} 14, \mathrm{~S} 15, \mathrm{~S} 16, \mathrm{~S} 17, \mathrm{~S} 18, \mathrm{~S} 19, \mathrm{~S} 20$ & \\
\hline
\end{tabular}

According to [45], the PM10 samples analyzed in this study can be associated with five different clusters, which are listed in Table 1. Main pollution sources contributing to each identified cluster are also given in Table 1, in addition to the main chemical fingerprints of each source [42]. Romano et al. [45] identified the sample clusters listed in Table 1 by mainly using the four-day 
analytical air mass back-trajectories (Figures SI9-SI23 of their paper). They used the HYbrid Single-Particle Lagrangian Integrated Trajectory (HYSPLIT) model version 4.8 from NOAA/ARL (https://www.ready.noaa.gov/; [46]). They identified a "desert dust" cluster composed of samples S3, S6, and S12 that were mainly characterized by a high concentration of elements associated with the "Natural Soil" source (Table 1). Samples S4, S7, and S8 represented the "marine" cluster (Table 1), characterized by $\mathrm{Al}, \mathrm{Ca}, \mathrm{Fe}, \mathrm{K}$, and $\mathrm{Si}$ abundances larger than $1 \%$, as well as a reduced $\mathrm{S}$ abundance, according to [42]. Then, the "continental" cluster composed of samples S1, S2, and S10 was also characterized by significant abundances of $\mathrm{Al}, \mathrm{Ca}, \mathrm{Fe}, \mathrm{K}, \mathrm{S}$, and $\mathrm{Si}$, all generally associated with anthropogenic-related pollution sources. The "late spring" cluster was mainly composed of chemical components typically associated with the "Natural Soil," "Agricultural Soil," and "Vegetative Burning" PM sources (Table 1). A "heavy rain" cluster was also identified by [45] during the analyzed monitoring campaign (Table 1).

Significant seasonal variations of the investigated chemical element mass concentrations can be observed from Figure 1: the winter samples (S1-S10) were clearly characterized by a larger variability with respect to the spring samples (S11-S20). In fact, in winter, low air temperatures associated with cloudy, wet, and stormy days likely contributed to the marked changes of the chemical species' mass concentrations in the collected samples. In contrast, the meteorological conditions occurring in spring all over the Mediterranean basin favored the air mass aging, enhanced natural and anthropogenic dust resuspension, and limited the removal of atmospheric particles by wet deposition. Therefore, the spring meteorological conditions contributed to a decrease of the PM chemical composition variability. Different previous works related to the PM main features at the study site proved the above-reported comments $[28,33,47]$.

\subsection{Oxidative Potential Characterization and Relationships with Metal, Br, $P, S$, and Se Total Concentration}

Figure 2 shows the temporal evolution of the DTT and AA volume- and mass-normalized OP responses during the analyzed period from January to June 2018. Observe from Figure 2 that $\mathrm{OP}_{\mathrm{V}} \mathrm{DTT}$ and $\mathrm{OP}_{\mathrm{V}} \mathrm{AA}$ values largely varied among the analyzed samples, both in winter and in spring. Such a large variability was probably due to the specific characteristics of the study site, where both the PM concentration and chemical composition were characterized by a high variability. The impact of long-range transported air masses from Northern and/or Eastern Europe (likely characterized by high anthropogenic pollution contributions) and from desert regions and the Mediterranean Sea (all surrounding Southeastern Italy) could be considered responsible for these results $[29,31,48-50]$. Figure 2 also shows that the $\mathrm{OP}_{\mathrm{V}} \mathrm{AA}$ response was, on average, significantly larger than the corresponding $\mathrm{OP}_{\mathrm{V}} \mathrm{DTT}$ response (with mean values \pm standard deviation (SD) equal to $0.35 \pm 0.11$ and $0.17 \pm 0.05 \mathrm{nmol} \mathrm{min}^{-1} \mathrm{~m}^{-3}$, respectively, as reported in Table 2). Perrone et al. [28] found a similar result when investigating autumn-winter PM10 $\mathrm{OP}_{\mathrm{V}}$ values. They explained that the larger $\mathrm{OP}_{\mathrm{V}} \mathrm{AA}$ values compared to those of $\mathrm{OP}_{\mathrm{V}} \mathrm{DTT}$ were mainly related to a different sensitivity of the two assays to some chemical species. In particular, they demonstrated by multi-linear regression analyses that the $\mathrm{OP}_{\mathrm{V}} \mathrm{AA}$ sensitivity to $\mathrm{K}^{+}$was significantly greater than that of $\mathrm{OP}_{\mathrm{V}} \mathrm{DTT}$. In this study, a significant seasonal variation was found only for the $\mathrm{OP}_{\mathrm{V}} \mathrm{AA}$ values (mean value equal to $0.32 \pm 0.08$ in winter and to $0.38 \pm 0.13$ in spring; Table 2). Different results were found by the authors of [51], who investigated the seasonal variability of $\mathrm{OP}_{\mathrm{V}} \mathrm{DTT}$ and $\mathrm{OP}_{\mathrm{V}} \mathrm{AA}$ values for PM10 samples monitored in Chamonix (France). They observed $\mathrm{OP}_{\mathrm{V}} \mathrm{AA}$ values that were significantly greater in winter than in summer, in contrast with the finding of this study. Note also from Figure 2 that the $\mathrm{OP}_{\mathrm{m}}$ assumed a lower variability range than $\mathrm{OP}_{\mathrm{v}}$, both for DTT and for AA assays. 


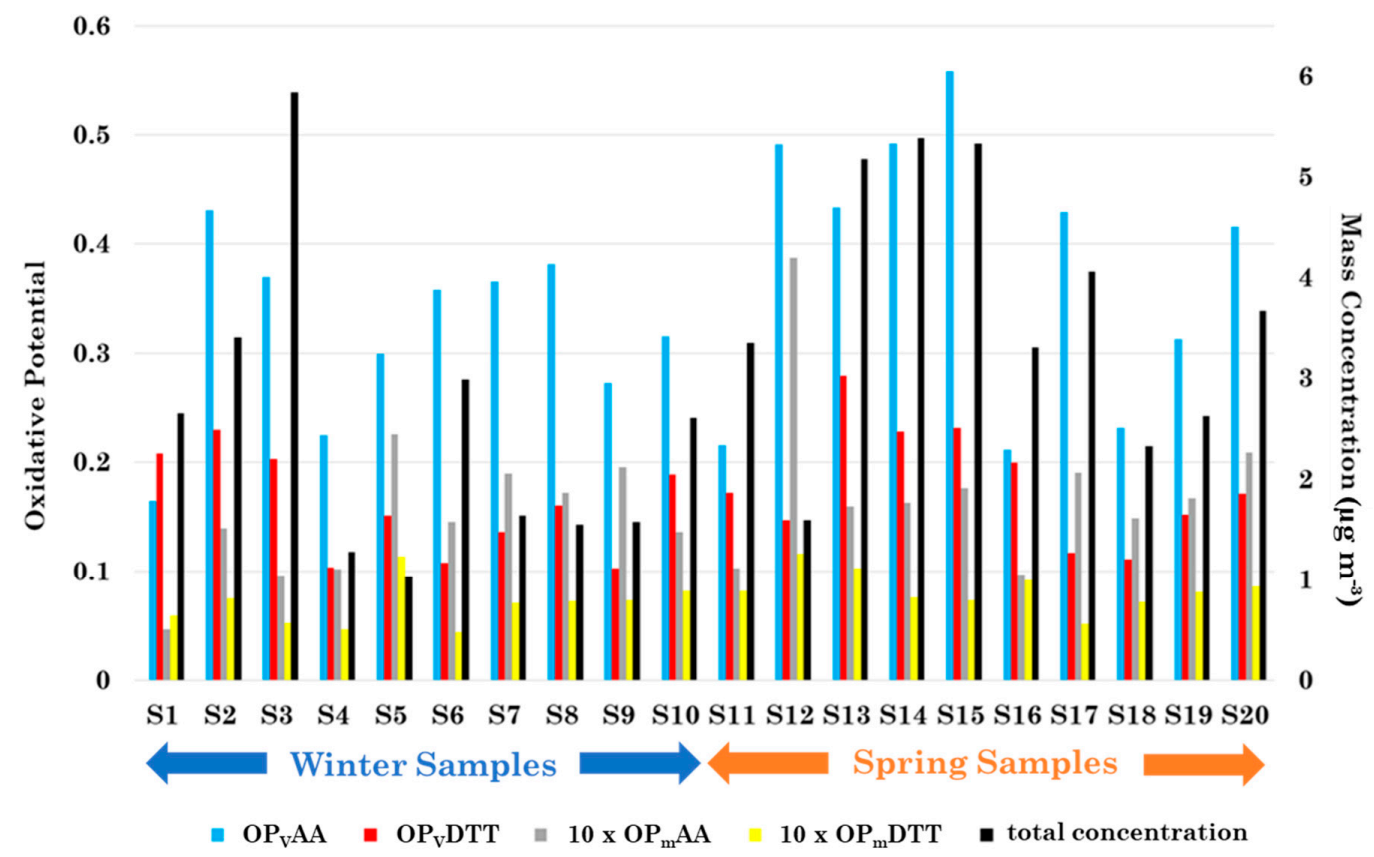

Figure 2. Temporal evolution of volume-normalized ascorbic acid- and dithiothreitol-oxidative potential $\left(\mathrm{OP}_{\mathrm{V}} \mathrm{AA}\right.$ and $\mathrm{OP}_{\mathrm{V}} \mathrm{DTT}$, respectively, expressed in $\mathrm{nmol} \mathrm{min}^{-1} \mathrm{~m}^{-3}$ ), mass-normalized ascorbic acidand dithiothreitol-oxidative potential $\left(\mathrm{OP}_{\mathrm{m}} \mathrm{AA}\right.$ and $\mathrm{OP}_{\mathrm{m}} \mathrm{DTT}$, respectively, expressed in $\mathrm{nmol} \mathrm{min}^{-1}$ $\left.\mu \mathrm{g}^{-1}\right)$, and the total mass concentration of all the analyzed chemical elements. $\mathrm{OP}_{\mathrm{m}} \mathrm{AA}$ and $\mathrm{OP}_{\mathrm{m}} \mathrm{DTT}$ values were multiplied by 10 to better visualize data.

Table 2. Mean values and standard deviations (SD) of PM10 volume- and mass-normalized oxidative potential responses $\left(\mathrm{OP}_{\mathrm{V}}\right.$ and $\mathrm{OP}_{\mathrm{m}}$, respectively) obtained from ascorbic acid (AA) and dithiothreitol (DTT) assays and total mass concentration of all the analyzed metals ( $\mathrm{Al}, \mathrm{As}, \mathrm{Ba}, \mathrm{Ca}, \mathrm{Cd}, \mathrm{Cr}, \mathrm{Cu}, \mathrm{Fe}, \mathrm{K}$, $\mathrm{Mn}, \mathrm{Mo}, \mathrm{Ni}, \mathrm{Pb}, \mathrm{Rb}, \mathrm{Si}, \mathrm{Sr}, \mathrm{Ti}, \mathrm{V}, \mathrm{Zn}$, and $\mathrm{Zr}$ ) and $\mathrm{Br}, \mathrm{P}, \mathrm{S}$, and Se. The data related to the total analyzed period, the 10 winter samples (from January to March 2018), and the 10 spring samples (from May to June 2018) are reported. Values with a significant seasonal difference (with $p$-value $<0.10$ ) are marked in bold.

\begin{tabular}{|c|c|c|c|c|c|c|}
\hline \multirow{2}{*}{ Oxidative Potential } & \multicolumn{2}{|c|}{ TOTAL } & \multicolumn{2}{|c|}{ WINTER } & \multicolumn{2}{|c|}{ SPRING } \\
\hline & Mean & SD & Mean & SD & Mean & SD \\
\hline $\begin{array}{c}\mathrm{OP}_{\mathrm{V}} \mathrm{AA} \\
\left(\mathrm{nmol}^{\mathrm{AA}} \min ^{-1} \mathrm{~m}^{-3}\right)\end{array}$ & 0.35 & 0.11 & 0.32 & 0.08 & 0.38 & 0.13 \\
\hline 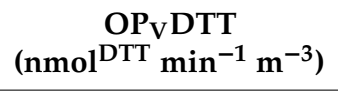 & 0.17 & 0.05 & 0.16 & 0.05 & 0.18 & 0.05 \\
\hline $\begin{array}{c}\mathrm{OP}_{\mathrm{m}} \mathrm{AA} \\
\left(\mathrm{nmol}^{\mathrm{AA}} \min ^{-1} \mu \mathrm{g}^{-1}\right)\end{array}$ & 0.016 & 0.007 & 0.014 & 0.005 & 0.018 & 0.008 \\
\hline $\begin{array}{c}\mathrm{OP}_{\mathrm{m}} \mathrm{DTT} \\
\left(\mathrm{nmol}^{\mathrm{DTT}} \mathrm{min}^{-1} \mu \mathrm{g}^{-1}\right)\end{array}$ & 0.008 & 0.002 & 0.007 & 0.002 & 0.008 & 0.002 \\
\hline $\begin{array}{l}\text { Total Mass } \\
\text { Concentration } \\
\left(\mu \mathrm{g} \mathrm{m}^{-3}\right)\end{array}$ & 3.1 & 1.5 & 2.5 & 1.4 & 3.7 & 1.3 \\
\hline
\end{tabular}

The main features of $\mathrm{OP}_{\mathrm{V}}$ and $\mathrm{OP}_{\mathrm{m}}$ previously described in this section were consistent with those reported by $[8,28]$ at the same site. In particular, Pietrogrande et al. [8] investigated the $\mathrm{OP}_{\mathrm{V}}$ and $\mathrm{OP}_{\mathrm{m}}$ seasonal trend in relation to the meteorological and atmospheric conditions and the PM10 chemical composition over a full year (from November 2014 to October 2015). They also proved that the $\mathrm{OP}_{\mathrm{V}}$ values from the DTT and AA assays had a similar association with the distinct chemical 
species analyzed in the PM10 samples, as also found by [15,52]. The two previous works on the OP characterization at the same site also demonstrated that the $\mathrm{OP}_{\mathrm{V}}$ response is an extensive parameter depending on the PM10 mass concentration, since high $\mathrm{OP}_{\mathrm{V}}$ responses were associated with high PM10 mass concentrations, according to [52]. Consequently, it is also particularly interesting to compare the $\mathrm{OP}_{\mathrm{V}}$ relationships with the total mass concentration of all analyzed chemical elements (black bars in Figure 2), which were also characterized by high variability during the analyzed period, as previously discussed in Section 3.1. In detail, the seasonal variation of the total mass concentration of all analyzed chemical components between winter and spring analyzed samples could be considered significant, as also proven by its corresponding mean values ( 2.5 and $3.7 \mu \mathrm{g} \mathrm{m}^{-3}$, respectively, as shown in Table 2$)$. The larger mean value of the chemical element mass concentration found in spring was mostly due to the larger occurrence of desert dust outbreaks that were responsible for the transport of crustal matter during the sampling time $[8,29,31]$. The seasonal variation of the total mass concentration was in agreement with the corresponding average increase of $\mathrm{OP}_{\mathrm{V}} \mathrm{AA}$ from winter to spring, as previously reported. In fact, observe from Figure 2 that the spring samples characterized by the highest total mass concentration (more than $5 \mu \mathrm{g} \mathrm{m}^{-3}$ for S13, S14, and S15) also presented larger values of OP $\mathrm{VAA}$ and $\mathrm{OP}_{\mathrm{V}} \mathrm{DTT}$ responses. Romano et al. [45] grouped S13, S14, and S15 as a "late spring sample" cluster (Table 1). S3 and S12, which were identified as "desert dust" samples by [45], assumed the largest value of the total mass concentration of the analyzed elements $\left(5.8 \mathrm{\mu g} \mathrm{m}^{-3}\right)$ and the largest value of $\mathrm{OP}_{\mathrm{m} A A}$ $\left(0.039 \mathrm{nmol} \mathrm{min}^{-1} \mu \mathrm{g}^{-1}\right)$. The "marine samples" S4, S7, and S8 (Table 1) assumed the lowest values of total mass concentration (less than $2 \mu \mathrm{g} \mathrm{m}^{-3}$ ), but they were also characterized by larger values of $\mathrm{OP}_{\mathrm{V}} \mathrm{AA}$. Conversely, the "continental samples" S1, S2, and S10 presented the highest value of total mass concentration of all analyzed chemical elements and the highest value of $\mathrm{OP}_{\mathrm{V}} \mathrm{DTT}$ among the winter samples. A similar variability between "desert dust" and "continental" PM10 samples was also found by the authors of [28], who analyzed the main features of $\mathrm{OP}_{\mathrm{V}} \mathrm{AA}, \mathrm{OP}_{\mathrm{V}} \mathrm{DTT}$, and PM chemical composition at the same site.

\subsection{Relationships between Metal, Br, $P, S$, and Se Concentration and Oxidative Potential by RDA}

A graphical view of the chemical element mass concentration-oxidative potential relationships is provided by the RDA triplot shown in Figure 3. As described in Section 2.3, this technique was applied to the metal, $\mathrm{Br}, \mathrm{P}, \mathrm{S}$, and Se concentration dataset as predictive variables and the oxidative potential dataset as dependent variables. More specifically, Figure 3 shows the RDA triplot relating the AA and DTT $\mathrm{OP}_{\mathrm{V}}$ and $\mathrm{OP}_{\mathrm{m}}$ responses (green arrows, dependent variables) to chemical element mass concentrations (red arrows, predictive variables) in (a) winter and (b) spring. Note that the arrow length and direction are strictly related to the variance that can be explained by analyzed variables [40]. Stronger correlations between two parameters involve a greater absolute value of the cosine of the angle between the two corresponding arrows. Arrows in the same and in the opposite direction suggest a positive and a negative correlation, respectively, among the corresponding variables [53].

Figure 3 shows that the red arrows associated with the analyzed chemical elements were, on average, spread in the canonical axis plane over a wider area in spring than in winter. The typical spring-summer air mass aging over the Mediterranean favored the mixing of particles of different types/sources $[29,50]$ and, therefore, likely contributed to this result. In contrast, OP green arrows were spread over a similar area of the canonical axis plane in winter and in spring (Figure 3a,b, respectively). Both OP response and chemical element arrow lengths were, on average, similar among winter and spring samples likely because the corresponding variables assumed a similar value of the explained variance among the two analyzed seasons. Conversely, OP responses (mainly for the AA assay) experienced a larger explained variance with respect to the analyzed chemical species concentrations, both in winter and in spring, as proven by their larger arrow length. In addition, note from Figure 3 that the $\mathrm{OP}_{\mathrm{V}}$ and the $\mathrm{OP}_{\mathrm{m}}$ arrows are located in a different region of the RDA triplot, proving their different features in relation to the metal, $\mathrm{Br}, \mathrm{P}, \mathrm{S}$, and Se concentrations. In fact, as reported in Section $2.2, \mathrm{OP}_{\mathrm{V}}$ represents an extensive parameter depending on the total mass concentration of the analyzed chemical 
elements, and, hence, this can likely be responsible for the lower angles between $\mathrm{OP}_{\mathrm{V}}$ and chemical element arrows in the RDA triplot. Conversely, $\mathrm{OP}_{\mathrm{m}}$ represents an intrinsic sample parameter that is not dependent on the total mass concentration of the analyzed chemical species, and, therefore, the corresponding arrows are located in a different area of the RDA triplot. Note also that the lower $\mathrm{OP}_{\mathrm{m}}$ variability range with respect to $\mathrm{OP}_{\mathrm{v}}$, both for the DTT and AA assays (as shown in Figure 2 and discussed in Section 3.2), could also have contributed to this last result. The angles between $\mathrm{OP}_{\mathrm{V}} \mathrm{AA}$ and $\mathrm{OP}_{\mathrm{V}} \mathrm{DTT}$ arrows and the angles between $\mathrm{OP}_{\mathrm{m}} \mathrm{AA}$ and $\mathrm{OP}_{\mathrm{m}} \mathrm{DTT}$ arrows are small and, likely, they highlight similar characteristics in relation to metal, Br, $\mathrm{P}, \mathrm{S}$, and Se concentrations. It is worth observing that these last relations are not dependent on the season, since they were similar both in winter and in spring (Figure 3a,b, respectively).
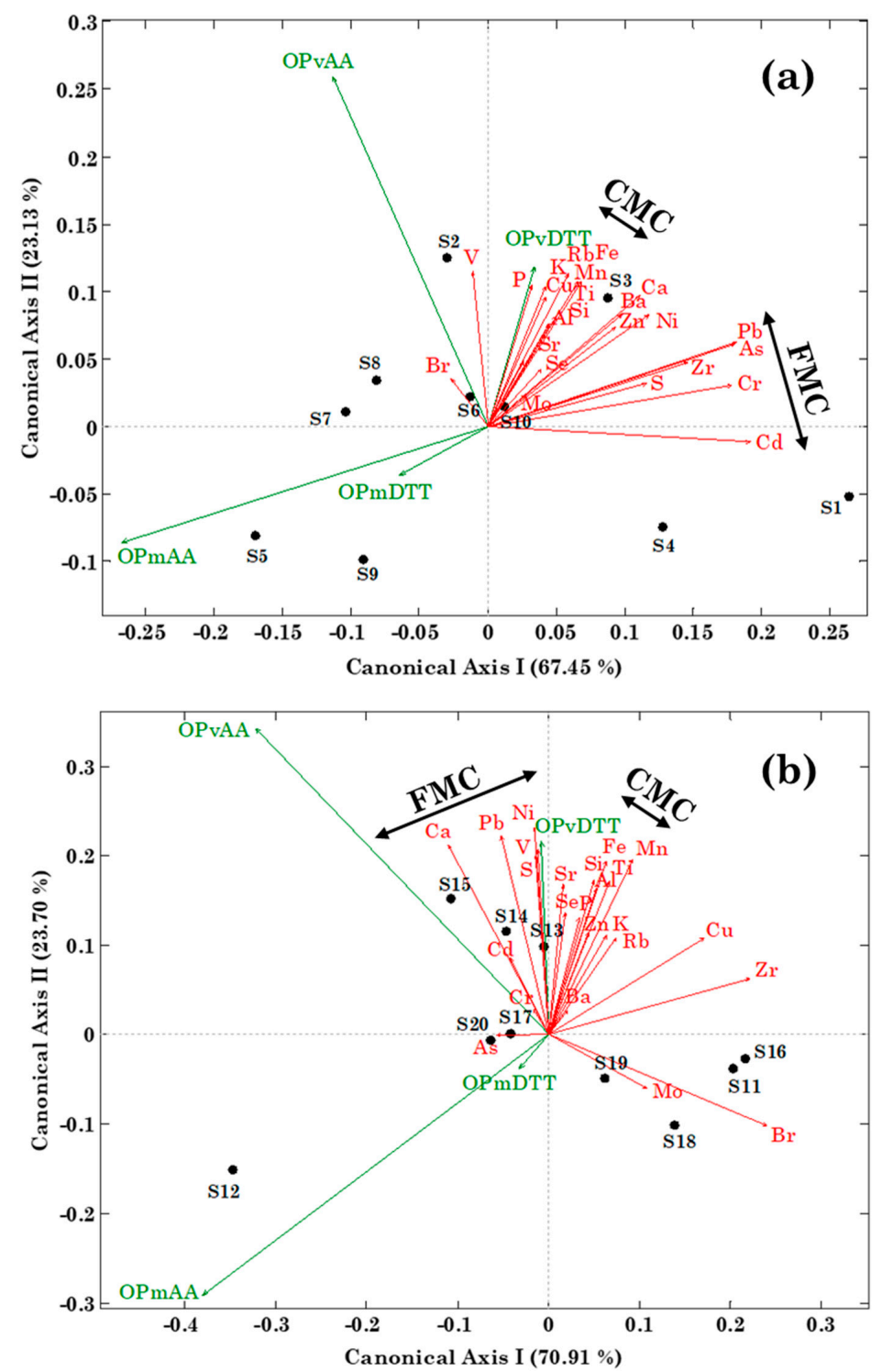

Figure 3. Ordination triplot based on the Redundancy Discriminant Analysis (RDA) between the mass concentrations of all analyzed chemical elements as predictive variables (red arrows), ascorbic acid and dithiothreitol volume-normalized oxidative potential $\left(\mathrm{OP}_{\mathrm{V}} \mathrm{AA}\right.$ and $\mathrm{OP}_{\mathrm{V}} \mathrm{DTT}$, respectively) and mass-normalized oxidative potential ( $\mathrm{OP}_{\mathrm{m}} \mathrm{AA}$ and $\mathrm{OP}_{\mathrm{m}} \mathrm{DTT}$, respectively) as response variables (green arrows), and detected samples (black full dots) in (a) winter and (b) spring. Black arrows indicate the two identified clusters (coarse-mode cluster (CMC) and fine-mode cluster (FMC)) based on the sources associated with the analyzed chemical elements. The total variance explained by the two RDA axes is also reported in parentheses. 
The RDA triplots reported in Figure 3 also allowed for the identification of some clusters of chemical species that could be associated with different pollution sources according to [42] and Table 1 . In particular, both in winter and in spring, two main clusters of chemical components can be clearly identified: a cluster related to both natural and anthropogenic sources mainly composed of $\mathrm{Al}, \mathrm{Fe}, \mathrm{Mn}$, $\mathrm{Si}$, and $\mathrm{Ti}$ (metals generally associated with coarse-mode crustal matter and/or road dust, denoted as $\mathrm{CMC}$ in Figure 3) and an anthropogenic source-related cluster that consists of $\mathrm{As}, \mathrm{Cd}, \mathrm{Cr}, \mathrm{Pb}$, and S (generally associated with fine-mode PM, denoted as FMC in Figure 3). According to the classification reported in [42], the main components of the metal coarse-mode cluster are included in the sources "Agriculture Soil," "Natural Soil," "Paved Road Dust," and "Unpaved Road Dust". Conversely, the chemical components of the fine-mode cluster are mainly associated with the sources "Smelter Fine," "Motor Vehicle," and "Oil Fire Power Plant". The selected clustering can be considered consistent with those reported in previous studies related to the characterization of PM sample chemical composition [54,55].

Winter and spring PM10 samples are also reported in Figure 3a,b, respectively, by black full dots. Only two main sample clusters could be identified in the winter RDA triplot (Figure 3a), according to the classification reported by [45]: the "marine" cluster composed of S7 and S8 and the "heavy rain" cluster composed of S5 and S9 (Table 1). The samples S7 and S8 were associated with air masses that crossed the Atlantic and the Mediterranean Sea before reaching the study site, according to [45]. In particular, the location of S7 and S8 is, on average, close to the $\mathrm{OP}_{\mathrm{V}} \mathrm{AA}$ arrow, which assumed higher values in the corresponding days, as previously discussed in Section 3.2. In fact, note that the location of the samples in the RDA triplot is close to the arrows associated with the metals and/or the other chemical elements that reached the highest concentrations in that sample and/or with the arrows related to the OP responses that assumed the highest values in that sample. Consequently, the winter sample S3, associated with the "desert dust" cluster by [45], is located very close to the arrows related to the "crustal matter" metals ( $\mathrm{Al}, \mathrm{Fe}, \mathrm{Mn}, \mathrm{Si}$, and Ti). Analogously, Figure 3a shows that the winter sample S1 (classified among the "continental" samples by [45]) is close to the "anthropogenic source-related" metals ( $\mathrm{As}, \mathrm{Cd}, \mathrm{Cr}, \mathrm{Pb}$ ) and $\mathrm{S}$. In contrast, Figure $3 \mathrm{~b}$ shows a larger variability in the location of the spring samples. As reported in Section 3.2, S13, S14, and S15 were the spring samples characterized by the highest total mass concentration of all the analyzed elements and also presented larger values of $\mathrm{OP}_{\mathrm{V}} \mathrm{AA}$ and $\mathrm{OP}_{\mathrm{V}} \mathrm{DTT}$ responses. As a consequence, the location of S13, S14, and S15, all grouped by [45] as "late spring samples" (Table 1) and characterized by a larger occurrence of desert dust advections, is close to the "crustal matter" metal, $\mathrm{OP}_{\mathrm{V}} \mathrm{AA}$, and $\mathrm{OP}_{\mathrm{V}} \mathrm{DTT}$ arrows. The highest value of $\mathrm{OP}_{\mathrm{m}} \mathrm{AA}$ measured during the day of the "desert dust" sample S12 explains its location in the RDA triplot. Note that the impact of long-range transported air masses on the ion and metal speciation of PM samples collected at the study site has been widely reported/discussed in several previous works $[29,31,56]$.

The oxidative potential response association with specific chemical elements represents one of the main outcomes of the RDA triplot. As previously discussed, the metals $\mathrm{Al}, \mathrm{Fe}, \mathrm{Mn}, \mathrm{Si}$, and Ti were strongly correlated with each other, ultimately defining a coarse-mode cluster $\mathrm{CMC}$, while the strong correlation among $\mathrm{As}, \mathrm{Cd}, \mathrm{Cr}, \mathrm{Pb}$, and $\mathrm{S}$ defined an anthropogenic source-related fine-mode cluster FMC. The RDA triplot reported in Figure 3 shows that the $\mathrm{OP}_{\mathrm{V}} \mathrm{DTT}$ arrow was located near the arrows related to the elements associated with the $\mathrm{CMC}$ (both in winter and in spring). The highest values of $\mathrm{OP}_{\mathrm{V}} \mathrm{DTT}$ associated with the highest values of the total mass concentration of the tested elements (S1, S2, and S10 in winter and S13, S14, and S15 in spring) could have contributed to this last result. Conversely, the location of $\mathrm{OP}_{\mathrm{V}} \mathrm{AA}$ in the RDA triplot is in a different area with respect to the chemical elements associated with the CMC and FMC clusters in winter (Figure 3a). In fact, the winter $\mathrm{OP}_{\mathrm{V}} \mathrm{AA}$ arrow is close to the "marine" cluster composed of S7 and S8 that is characterized by low concentrations of metals, $\mathrm{Br}, \mathrm{P}, \mathrm{S}$, and Se. In spring, the $\mathrm{OP}_{\mathrm{V}} \mathrm{AA}$ arrow is close to the FMC arrows, probably strictly related to higher $\mathrm{OP}_{\mathrm{V}} \mathrm{AA}$ values associated with higher total mass concentration of the tested chemical elements (in particular, samples S13, S14, and S15), as shown in Figure 2. Different relationships 
between $\mathrm{OP}_{\mathrm{m}}$ and specific chemical elements, with similar seasonal features, can be observed in the RDA triplot. In fact, both $\mathrm{OP}_{\mathrm{m}} \mathrm{AA}$ and $\mathrm{OP}_{\mathrm{m}} \mathrm{DTT}$ arrows are located in opposite directions with respect to both metal CMC and FMC clusters (Figure 3), showing out an anti- correlation between $\mathrm{OP}_{\mathrm{m}}$ responses and the analyzed chemical element concentrations. Note that, as previously discussed, $\mathrm{OP}_{\mathrm{m}}$ is an intrinsic parameter that is not related to the mass concentration of specific chemical species. In conclusion, Figure 3 and the above reported comments show that the clustering of some chemical elements in the analyzed PM10 samples allowed for the inference of the main pollution sources and, hence, their association with OP values.

\subsection{Relationships between Metal, Br, P, S and Se Concentration and Oxidative Potential by Spearman Correlation Coefficients}

The relationships between oxidative potential responses and chemical element concentrations were also analyzed by Spearman correlation coefficients $(r)$ for both winter and spring samples. The main goals of this section are to highlight the relationship strengths, identify the main elements responsible for the relationships, and compare the results from the correlation coefficient analysis with corresponding RDA results. Table 3 summarizes significant positive and negative relationships between OP responses and metal, Br, P, S, and Se mass concentrations for both winter and spring samples. The Spearman correlation coefficients, with values significant at $p$-levels of $<0.01$ and 0.05 in bold and in bold-italic, respectively, are reported in Table S2 for all the analyzed parameters.

Table 3. AA and DTT volume- and mass-normalized oxidative potential responses $\left(\mathrm{OP}_{\mathrm{V}}\right.$ and $\mathrm{OP}_{\mathrm{m}}$, respectively) positively and negatively correlated with total (all analyzed chemical elements) and PM10 mass concentration for the 10 winter samples and the 10 spring samples. Spearman correlation coefficients are reported in brackets (values significant at $p$-levels of $<0.01$ and 0.05 are in bold and in italics, respectively).

\begin{tabular}{|c|c|c|}
\hline & WINTER & SPRING \\
\hline OPVAA & & $\mathrm{OP}_{\mathrm{m}} \mathrm{AA}(0.67), \mathrm{Br}(-0.65)$ \\
\hline OPVDTT & $\begin{array}{c}\text { PM10 (0.67), } \mathrm{Ba}(0.68), \mathrm{Cr}(\mathbf{0 . 8 5}), \mathrm{Ni}(\mathbf{0 . 8 5}), \mathrm{Pb}(0.70), \mathrm{P} \\
(\mathbf{0 . 8 5}), \mathrm{K}(\mathbf{0 . 9 7}), \mathrm{Ca}(0.73), \mathrm{Mn}(0.65), \mathrm{Fe}(0.69), \mathrm{Cu}(\mathbf{0 . 9 4}) \\
\mathrm{Zn}(\mathbf{0 . 8 5}), \mathrm{Rb}(\mathbf{0 . 8 4}), \mathrm{Zr}(0.67)\end{array}$ & $\begin{array}{l}\text { PM10 (0.82), Pb (0.80), P (0.76), Ca } \\
\quad(0.72), \mathrm{Fe}(0.63), \mathrm{Zn}(0.66)\end{array}$ \\
\hline $\mathrm{OP}_{\mathrm{m}} \mathbf{A A}$ & $\begin{array}{c}\text { PM10 (-0.77), As }(-0.87), \mathrm{Cd}(-0.86), \mathrm{Pb}(-0.92), \mathrm{S} \\
(-0.63), \mathrm{Zn}(-0.70)\end{array}$ & $\mathrm{OP}_{\mathrm{V}} \mathrm{AA}(0.67)$ \\
\hline $\mathrm{OP}_{\mathrm{m}} \mathrm{DTT}$ & & \\
\hline
\end{tabular}

According to the Spearman correlation coefficients reported in Table 3, different relationships between $\mathrm{OP}$ responses and specific chemical element concentrations could be found in winter and in spring. The $\mathrm{OP}_{\mathrm{V}} \mathrm{DTT}$ values were correlated with a larger number of elements in winter than in spring. More specifically, the winter $\mathrm{OP}_{\mathrm{V}} \mathrm{DTT}$ values were characterized by strong correlations with metals associated with the anthropogenic sources (such as $\mathrm{Cr}, \mathrm{Ni}, \mathrm{Cu}$, and $\mathrm{Zn}$ ) and chemical elements associated with the natural sources (such as $\mathrm{K}$ and $\mathrm{P}$ ), according to [42]. This last result is consistent with those reported by $[8,28]$ at the study site. The previous results outlined from the Spearman correlation coefficients appear to contrast with the RDA outcomes, indicating strong correlations of winter $\mathrm{OP}_{\mathrm{V}} \mathrm{DTT}$, but only with some elements related to natural sources and/or road dust. Significant winter $\mathrm{OP}_{\mathrm{V}} \mathrm{DTT}$-related Spearman correlation coefficients with lower $p$-values were also found with other metals generally associated with some natural sources and/or road dust (such as $\mathrm{Ca}, \mathrm{Mn}$, and $\mathrm{Fe}$ ) and metals characterized by very low concentrations (such as $\mathrm{Ba}, \mathrm{Rb}$, and $\mathrm{Zr}$ ). As one can observe from Table 3, a smaller amount of chemical elements $(\mathrm{Pb}, \mathrm{P}, \mathrm{Ca}, \mathrm{Fe}$, and $\mathrm{Zn})$ was correlated with $\mathrm{OP}_{\mathrm{V}} \mathrm{DTT}$ in spring. Nishita-Hara et al. [26] sampled both fine and coarse PM particles in spring 2016 in Fukuoka (Japan). According to the results of this study, they found a significant correlation of $\mathrm{OP}_{\mathrm{V}} \mathrm{DTT}$ with Fe in the PM coarse-mode fraction, which they mainly associated with mineral dust events. They also 
found that $\mathrm{OP}_{\mathrm{V}} \mathrm{DTT}$ was associated with $\mathrm{Pb}$ in $\mathrm{PM}$ fine-mode fraction, likely due to anthropogenic combustion sources. Calas et al. [19] also reported a strong correlation between $\mathrm{OP}_{\mathrm{V}} \mathrm{DTT}$ response and Fe mass concentration $(r=0.71$, significant with a $p$-level $<0.01)$ in PM10 samples monitored in Chamonix (France). The latter results from Spearman correlation coefficients are not consistent with the previously reported RDA outcomes (Figure 3), thus indicating relationships between spring $\mathrm{OP}_{\mathrm{V}} \mathrm{DTT}$ and several element concentrations, related to both natural and anthropogenic sources. Note also from Table 3 that $\mathrm{OP}_{\mathrm{V}} \mathrm{DTT}$ was correlated with PM10 mass concentration both in winter and in spring, since it represents an extensive parameter (Section 2.2). Accordingly, the highest values of $\mathrm{OP}_{\mathrm{V}} \mathrm{DTT}$ were associated with the highest values of the total mass concentration of all the analyzed chemical elements (S1, S2, and S10 in winter and S13, S14, and S15 in spring), as shown in Figure 2. Janssen et al. [52] also found a strong correlation between $\mathrm{OP}_{\mathrm{V}} \mathrm{DTT}$ and PM10 mass concentration $(r=0.75$, significant with $p$-level $<0.01)$ when analyzing some PM10 samples from March to October 2009 in different sites of the Netherlands.

The main results from Spearman correlation coefficient analysis on the winter $\mathrm{OP}_{\mathrm{V}} \mathrm{AA}$ relationships with chemical components were in reasonable accordance with the corresponding ones from RDA. In fact, $\mathrm{OP}_{\mathrm{V}} \mathrm{AA}$ response did not present any correlations with specific element concentrations in winter. The higher values of $\mathrm{OP}_{\mathrm{V}} \mathrm{AA}$ found in relation to the "marine" cluster composed of S7 and S8 that was characterized by low chemical element mass concentrations could have likely contributed to this last result. In spring, $\mathrm{OP}_{\mathrm{V}} \mathrm{AA}$ assumed an inverse correlation with $\mathrm{Br}$, which is generally associated with anthropogenic sources according to [42]. Accordingly, the RDA outcomes indicated a strong relation between $\mathrm{OP}_{\mathrm{V}} \mathrm{AA}$ and the anthropogenic cluster in spring (Figure 3b).

The winter $\mathrm{OP}_{\mathrm{m}} \mathrm{AA}$ was anti-correlated with the mass concentration of some chemical species generally associated with anthropogenic sources ( $\mathrm{As}, \mathrm{Cd}, \mathrm{Pb}, \mathrm{S}$, and $\mathrm{Zn}$ ), in agreement with the RDA outcomes (Figure 3a). OP $\mathrm{m}$ DTT did not present correlations with any element concentrations, both in winter and in spring. The corresponding small length of the OP $\mathrm{mTT}$ arrow in the RDA triplot is consistent with this result, indicating a reduced variance explained by $\mathrm{OP}_{\mathrm{m}} \mathrm{DTT}$ in the analyzed samples.

Table 3 showed that the relations of a given OP response with a specific chemical element presented some seasonal characteristics, in accordance with RDA results. To further investigate these mean seasonal variations among the analyzed parameters, Figure $4 \mathrm{a}, \mathrm{b}$ shows the $\mathrm{OP}_{\mathrm{V}}$ responses, and Figure $4 \mathrm{c}, \mathrm{d}$ shows the $\mathrm{OP}_{\mathrm{m}}$ responses as a function of the total mass concentration of the analyzed chemical elements for both the winter (blue circles) and spring (red circles) samples. $\mathrm{OP}_{\mathrm{V}} \mathrm{DTT}$ assumed the largest correlation coefficients with respect to the total mass concentration due to all chemical species $(r=0.58$ in winter and $r=0.75$ in spring, both significant at a $p$-level $<0.05)$, as suggested by the large number of specific mass concentrations correlated with $\mathrm{OP}_{\mathrm{V}} \mathrm{DTT}$ responses (Table 3 ). As shown in Figure 2, the highest values of $\mathrm{OP}_{\mathrm{V}} \mathrm{DTT}$ associated with the highest values of chemical species mass concentration (S1, S2, and S10 in winter and S13, S14, and S15 in spring) also likely contributed to this last result. $\mathrm{OP}_{\mathrm{V}} \mathrm{AA}$ also showed an increasing trend as a function of total mass concentration (Figure 4a), but it was characterized by a not significant correlation coefficient $(r=0.34$ in winter and $\mathrm{r}=0.49$ in spring). The higher winter values of $\mathrm{OP}_{\mathrm{V}} \mathrm{AA}$ were found in relation to the "marine" samples S7 and S8 that were characterized by low total mass concentrations, and, therefore, this could have probably contributed to the low $r$ value in winter. The low number of specific elements correlated with $\mathrm{OP}_{\mathrm{V}} \mathrm{AA}$ also confirmed the results of Figure $4 \mathrm{a}$. A slight decreasing trend of $\mathrm{OP}_{\mathrm{m}}$ response as a function of the total mass concentration was found (Figure $4 c, d$ ). Only the correlation coefficient between $\mathrm{OP}_{\mathrm{m}} \mathrm{AA}$ and total concentration in winter $(\mathrm{r}=-0.52)$ was significant (at a $p$-level $<0.10$ ), in agreement with the larger number of specific element concentrations anti-correlated with $\mathrm{OP}_{\mathrm{m}} \mathrm{AA}$ (Table 3). 

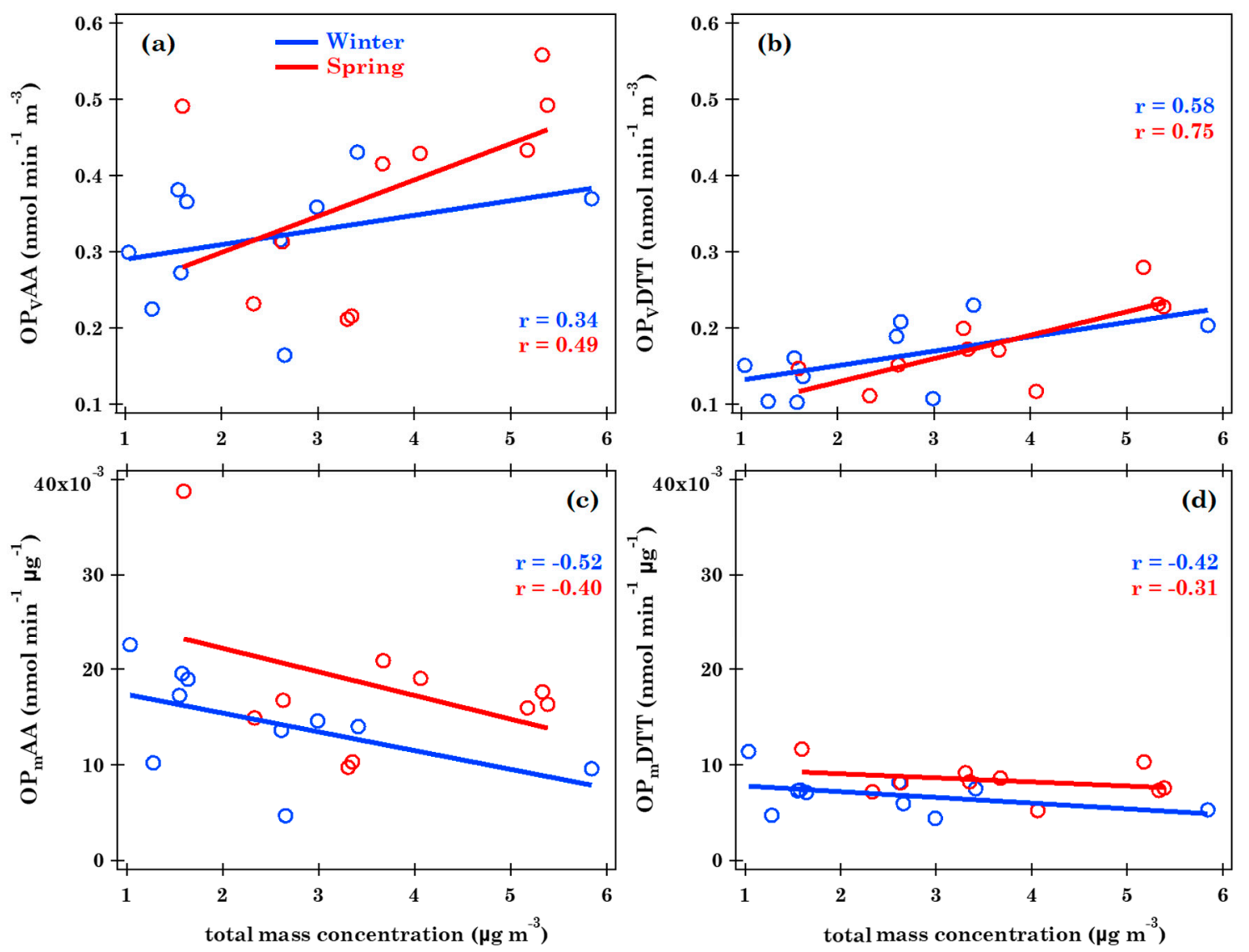

Figure 4. Scatterplot of the (a) ascorbic acid and (b) dithiothreitol volume-normalized oxidative potential $\left(\mathrm{OP}_{\mathrm{V}} \mathrm{AA}\right.$ and $\mathrm{OP}_{\mathrm{V}} \mathrm{DTT}$, respectively) and the (c) ascorbic acid and (d) dithiothreitol mass-normalized oxidative potential $\left(\mathrm{OP}_{\mathrm{m}} \mathrm{AA}\right.$ and $\mathrm{OP}_{\mathrm{m}} \mathrm{DTT}$, respectively) as a function of the mass concentration of all the analyzed chemical elements (Al, As, Ba, Br, Ca, Cd, Cr, Cu, Fe, K, Mn, Mo, Ni, P, Pb, Rb, S, Se, Si, $\mathrm{Sr}, \mathrm{Ti}, \mathrm{V}, \mathrm{Zn}$, and $\mathrm{Zr}$ ) for the 10 winter samples (blue circles) and the 10 spring samples (red circles). The correlation coefficients $r$ and the corresponding fitting lines are also reported in each plot.

The results previously reported in this section showed some contrasting results between the analysis of Spearman correlation coefficients and RDA about the determination of relationship strengths and the identification of the main chemical elements responsible for the relationships with oxidative potential responses. The discrepancies between Spearman coefficient results (Table 3) and RDA triplots (Figure 3) were likely due to the fact that the location of a specific arrow in the RDA triplot is dependent on more factors (mainly the sample location in the plot, the chemical element relationships with other elements, and the relationships of OP values with chemical elements) that may contrast among them. Conversely, Spearman correlation coefficients link the relationship between two specific parameters.

\section{Conclusions}

Redundancy Discriminant Analysis and Spearman correlation coefficients were used in this work to investigate the oxidative potential sensitivity to the mass concentration of specific chemical elements (metals, Br, P, S, and Se) in PM10 samples. The monitoring was performed from January to June 2018 in an Italian coastal site of the Central Mediterranean away from large sources of local pollution. Dithiothreitol and ascorbic acid acellular assays and the particle-induced X-ray emission technique were used to estimate oxidative potential responses and mass concentrations of 24 specific chemical elements, respectively. The main results of this study are reported below.

$\mathrm{Al}, \mathrm{Ca}, \mathrm{Fe}, \mathrm{K}, \mathrm{S}$, and $\mathrm{Si}$ were the most abundant chemical elements among those analyzed in the detected samples, both in winter and in spring. They were associated both with natural 
sources like soil and/or desert dust and with anthropogenic sources like road dust. Total and specific mass concentrations assumed significant seasonal variations: winter samples were clearly characterized by a larger variability with respect to spring samples, mainly because of the different meteorological conditions.

$\mathrm{OP}_{\mathrm{V}} \mathrm{DTT}$ and $\mathrm{OP}_{\mathrm{V}} \mathrm{AA}$ were both characterized by a large variability among the analyzed samples, both in winter and in spring, a variability that was, in turn, related to the large variability of PM concentration and chemical composition. The $\mathrm{OP}_{\mathrm{V}} \mathrm{AA}$ response was, on average, significantly larger than the corresponding $\mathrm{OP}_{\mathrm{V}} \mathrm{DTT}$ response, and its significant seasonal variation was consistent with that of the total mass concentration of all the analyzed chemical elements. $\mathrm{OP}_{\mathrm{m}}$ assumed a lower variability range than $\mathrm{OP}_{\mathrm{v}}$, both for the DTT and AA assays.

The RDA-which was applied to oxidative potential responses as dependent variables and metal, Br, P, S, and Se concentrations as explanatory variables-allowed to visualize main relations between PM10 oxidative potential and the corresponding concentration of specific chemical elements. A coarse-mode cluster related to both natural and anthropogenic sources (such as desert dust and road dust, respectively) and a fine-mode cluster related only to anthropogenic sources were identified by RDA. OP ${ }_{V} D T T$ was mainly related to the chemical elements associated with the coarse-mode cluster (both in winter and in spring), while $\mathrm{OP}_{\mathrm{V}} \mathrm{AA}$ was associated with the fine-mode cluster only in spring.

Spearman correlation coefficients were used to compare the main RDA results contributing to the evaluation of benefits and limits of both used techniques. According to Spearman correlation coefficients, winter $\mathrm{OP}_{\mathrm{V}} \mathrm{DTT}$ was characterized by strong correlations with metals associated with anthropogenic sources (such as $\mathrm{Cr}, \mathrm{Ni}, \mathrm{Cu}$, and $\mathrm{Zn}$ ) and with chemical elements related to natural sources (such as $\mathrm{K}$ and $\mathrm{P}$ ). Conversely, less element mass concentrations ( $\mathrm{Pb}, \mathrm{P}, \mathrm{Ca}, \mathrm{Fe}$, and $\mathrm{Zn}$ ) were correlated with $\mathrm{OP}_{\mathrm{V}} \mathrm{DTT}$ in spring. $\mathrm{OP}_{\mathrm{V}} \mathrm{AA}$ response did not present any correlations with specific element mass concentrations. Both RDA triplots and Spearman coefficients suggested an anti-correlation between $\mathrm{OP}_{\mathrm{m}}$ responses and specific chemical element concentrations.

In conclusion, this work has contributed to the validation of the main results from previous studies related to the OP characterization over Southeastern Italy. In addition, it represents the first work relating PM OP responses and specific chemical elements (metals, Br, P, S, and Se) by the RDA technique. Its main results have demonstrated that the integrated approach based on both RDA and Spearman correlation coefficients can provide new insights about the relations between OP responses and chemical element concentrations. We are aware that the RDA technique can be affected by different factors (e.g., sample location in the plot, chemical element relationships with other elements, OP relationships with all the analyzed chemical elements), while the Spearman correlation coefficients depend only on the relations between two specific parameters. However, their integration can contribute to the better evaluation of harmful effects associated with specific chemical components in PM samples.

Supplementary Materials: The following are available online at http://www.mdpi.com/2073-4433/11/4/367/s1, Table S1: Dataset of PM10 mass concentration, ascorbic acid and dithiothreitol volume- and mass-normalized oxidative potential, and mass concentration of all analyzed chemical elements, Table S2: Spearman correlation coefficients between PM10 mass concentration, ascorbic acid and dithiothreitol volume- and mass-normalized oxidative potential, and mass concentration of all analyzed chemical elements.

Author Contributions: Conceptualization, S.R.; methodology, S.R., S.B., F.L., and M.R.; software, S.R.; formal analysis, S.R.; investigation, S.R.; measurements, S.B., F.L., and M.R.; writing-original draft preparation, S.R.; supervision, S.R. and M.C.P. All authors have read and agreed to the published version of the manuscript.

Funding: S. Romano has carried out this work with the support of a Temporary Researcher position financed by the Italian "Programma Operativo Nazionale (PON) Ricerca e Innovazione 2014-2020 (Azione I.2-Attrazione e Mobilità dei Ricercatori)". The work was partially supported by the PON project "PER-ACTRIS-IT_Potenziamento della componente italiana dell'Infrastruttura di Ricerca Aerosol, Clouds and Trace Gases Research Infrastructure" and by the Italian INFN (Istituto Nazionale Fisica Nucleare), in the frame of the projects TRACCIA (Time Resolved Aerosol Characterisation: Challenging Improvements and Ambitions) and IS-ABS (Integrated System for Aerosol and Bioaerosol Studies at the Pierre Auger Observatory). 
Conflicts of Interest: The authors declare no conflict of interest. The funders had no role in the design of the study; in the collection, analyses, or interpretation of data; in the writing of the manuscript; or in the decision to publish the results.

\section{References}

1. Kelly, F.J.; Fussell, J.C. Size, source and chemical composition as determinants of toxicity attributable to ambient particulate matter. Atmos. Environ. 2012, 60, 504-526. [CrossRef]

2. Fortoul, T.I.; Rodriguez-Lara, V.; Gonzalez-Villalva, A.; Rojas-Lemus, M.; Colin-Barenque, L.; Bizarro-Nevares, P.; García-Peláez, I.; Ustarroz-Cano, M.; López-Zepeda, S.; Cervantes-Yépez, S.; et al. Health Effects of Metals in Particulate Matter. Curr. Air Qual. Issues 2015. [CrossRef]

3. Englert, N. Fine particles and human health-A review of epidemiological studies. Toxicol. Lett. 2004, 149, 235-242. [CrossRef] [PubMed]

4. Lippmann, M.; Chen, L.-C.; Gordon, T.; Ito, K.; Thurston, G.D. National Particle Component Toxicity (NPACT) Initiative: Integrated epidemiologic and toxicologic studies of the health effects of particulate matter components. Res. Rep. Health Eff. Inst. 2013, 177, 5-13.

5. Zhou, J.; Ito, K.; Lall, R.; Lippmann, M.; Thurston, G. Time-Series Analysis of Mortality Effects of Fine Particulate Matter Components in Detroit and Seattle. Environ. Health Perspect. 2011, 119, 461-466. [CrossRef]

6. Cakmak, S.; Dales, R.; Kauri, L.M.; Mahmud, M.; Van Ryswyk, K.; Vanos, J.; Liu, L.; Kumarathasan, P.; Thomson, E.; Vincent, R.; et al. Metal composition of fine particulate air pollution and acute changes in cardiorespiratory physiology. Environ. Pollut. 2014, 189, 208-214. [CrossRef]

7. Ayres, J.G.; Borm, P.; Cassee, F.R.; Castranova, V.; Donaldson, K.; Ghio, A.; Harrison, R.M.; Hider, R.; Kelly, F.; Kooter, I.M.; et al. Evaluating the Toxicity of Airborne Particulate Matter and Nanoparticles by Measuring Oxidative Stress Potential-A Workshop Report and Consensus Statement. Inhal. Toxicol. 2008, 20, 75-99. [CrossRef]

8. Pietrogrande, M.C.; Perrone, M.R.; Manarini, F.; Romano, S.; Udisti, R.; Becagli, S. PM10 oxidative potential at a Central Mediterranean Site: Association with chemical composition and meteorological parameters. Atmos. Environ. 2018, 188, 97-111. [CrossRef]

9. Borm, P.J.A.; Kelly, F.; Künzli, N.; Schins, R.P.F.; Donaldson, K. Oxidant generation by particulate matter: From biologically effective dose to a promising, novel metric. Occup. Environ. Med. 2007, 64, 73-74. [CrossRef]

10. Janssen, N.A.H.; Strak, M.; Yang, A.; Hellack, B.; Kelly, F.J.; Kuhlbusch, T.A.J.; Harrison, R.M.; Brunekreef, B.; Cassee, F.R.; Steenhof, M.; et al. Associations between three specific a-cellular measures of the oxidative potential of particulate matter and markers of acute airway and nasal inflammation in healthy volunteers. Occup. Environ. Med. 2015, 72, 49-56. [CrossRef]

11. Brook, R.D.; Rajagopalan, S.; Pope, C.A.; Brook, J.R.; Bhatnagar, A.; Diez-Roux, A.V.; Holguin, F.; Hong, Y.; Luepker, R.V.; Mittleman, M.A.; et al. Particulate Matter Air Pollution and Cardiovascular Disease: An Update to the Scientific Statement From the American Heart Association. Circulation 2010, 121, 2331-2378. [CrossRef] [PubMed]

12. Nel, A. Air Pollution-Related Illness: Effects of Particles. Science 2005, 308, 804-806. [CrossRef] [PubMed]

13. Weichenthal, S.A.; Godri Pollitt, K.; Villeneuve, P.J. PM2.5, oxidant defence and cardiorespiratory health: A review. Environ. Health 2013, 12, 40. [CrossRef] [PubMed]

14. Crobeddu, B.; Aragao-Santiago, L.; Bui, L.-C.; Boland, S.; Baeza Squiban, A. Oxidative potential of particulate matter 2.5 as predictive indicator of cellular stress. Environ. Pollut. 2017, 230, 125-133. [CrossRef] [PubMed]

15. Yang, A.; Jedynska, A.; Hellack, B.; Kooter, I.; Hoek, G.; Brunekreef, B.; Kuhlbusch, T.A.J.; Cassee, F.R.; Janssen, N.A.H. Measurement of the oxidative potential of PM2.5 and its constituents: The effect of extraction solvent and filter type. Atmos. Environ. 2014, 83, 35-42. [CrossRef]

16. Yang, A.; Wang, M.; Eeftens, M.; Beelen, R.; Dons, E.; Leseman, D.L.A.C.; Brunekreef, B.; Cassee, F.R.; Janssen, N.A.H.; Hoek, G. Spatial Variation and Land Use Regression Modeling of the Oxidative Potential of Fine Particles. Environ. Health Perspect. 2015, 123, 1187-1192. [CrossRef] [PubMed]

17. Kelly, F.; Armstrong, B.; Atkinson, R.; Anderson, H.R.; Barratt, B.; Beevers, S.; Cook, D.; Green, D.; Derwent, D.; Mudway, I.; et al. The London low emission zone baseline study. Res. Rep. Health Eff. Inst. 2011, 163, 3-79. 
18. Szigeti, T.; Óvári, M.; Dunster, C.; Kelly, F.J.; Lucarelli, F.; Záray, G. Changes in chemical composition and oxidative potential of urban PM2.5 between 2010 and 2013 in Hungary. Sci. Total Environ. 2015, 518-519, 534-544. [CrossRef]

19. Calas, A.; Uzu, G.; Kelly, F.J.; Houdier, S.; Martins, J.M.F.; Thomas, F.; Molton, F.; Charron, A.; Dunster, C.; Oliete, A.; et al. Comparison between five acellular oxidative potential measurement assays performed with detailed chemistry on $\mathrm{PM}_{10}$ samples from the city of Chamonix (France). Atmos. Chem. Phys. 2018, 18, 7863-7875. [CrossRef]

20. Calas, A.; Uzu, G.; Besombes, J.-L.; Martins, J.M.F.; Redaelli, M.; Weber, S.; Charron, A.; Albinet, A.; Chevrier, F.; Brulfert, G.; et al. Seasonal Variations and Chemical Predictors of Oxidative Potential (OP) of Particulate Matter (PM), for Seven Urban French Sites. Atmosphere 2019, 10, 698. [CrossRef]

21. Weichenthal, S.; Crouse, D.L.; Pinault, L.; Godri-Pollitt, K.; Lavigne, E.; Evans, G.; van Donkelaar, A.; Martin, R.V.; Burnett, R.T. Oxidative burden of fine particulate air pollution and risk of cause-specific mortality in the Canadian Census Health and Environment Cohort (CanCHEC). Environ. Res. 2016, 146, 92-99. [CrossRef] [PubMed]

22. Liu, L.; Urch, B.; Szyszkowicz, M.; Evans, G.; Speck, M.; Van Huang, A.; Leingartner, K.; Shutt, R.H.; Pelletier, G.; Gold, D.R.; et al. Metals and oxidative potential in urban particulate matter influence systemic inflammatory and neural biomarkers: A controlled exposure study. Environ. Int. 2018, 121, 1331-1340. [CrossRef] [PubMed]

23. Daher, N.; Saliba, N.A.; Shihadeh, A.L.; Jaafar, M.; Baalbaki, R.; Shafer, M.M.; Schauer, J.J.; Sioutas, C. Oxidative potential and chemical speciation of size-resolved particulate matter (PM) at near-freeway and urban background sites in the greater Beirut area. Sci. Total Environ. 2014, 470-471, 417-426. [CrossRef] [PubMed]

24. Charrier, J.G.; Anastasio, C. On dithiothreitol (DTT) as a measure of oxidative potential for ambient particles: Evidence for the importance of soluble transition metals. Atmos. Chem. Phys. 2012, 12, 9321-9333. [CrossRef]

25. Mudway, I.S.; Stenfors, N.; Duggan, S.T.; Roxborough, H.; Zielinski, H.; Marklund, S.L.; Blomberg, A.; Frew, A.J.; Sandström, T.; Kelly, F.J. An in vitro and in vivo investigation of the effects of diesel exhaust on human airway lining fluid antioxidants. Arch. Biochem. Biophys. 2004, 423, 200-212. [CrossRef]

26. Nishita-Hara, C.; Hirabayashi, M.; Hara, K.; Yamazaki, A.; Hayashi, M. Dithiothreitol-Measured Oxidative Potential of Size-Segregated Particulate Matter in Fukuoka, Japan: Effects of Asian Dust Events. GeoHealth 2019, 3, 160-173. [CrossRef]

27. Saffari, A.; Daher, N.; Shafer, M.M.; Schauer, J.J.; Sioutas, C. Seasonal and spatial variation in dithiothreitol (DTT) activity of quasi-ultrafine particles in the Los Angeles Basin and its association with chemical species. J. Environ. Sci. Health A 2014, 49, 441-451. [CrossRef]

28. Perrone, M.R.; Bertoli, I.; Romano, S.; Russo, M.; Rispoli, G.; Pietrogrande, M.C. PM2.5 and PM10 oxidative potential at a Central Mediterranean Site: Contrasts between dithiothreitol- and ascorbic acid-measured values in relation with particle size and chemical composition. Atmos. Environ. 2019, 210, 143-155. [CrossRef]

29. Perrone, M.R.; Romano, S.; Orza, J.A.G. Columnar and ground-level aerosol optical properties: Sensitivity to the transboundary pollution, daily and weekly patterns, and relationships. Environ. Sci. Pollut. Res. 2015, 22, 16570-16589. [CrossRef]

30. Basart, S.; Pérez, C.; Cuevas, E.; Baldasano, J.M.; Gobbi, G.P. Aerosol characterization in Northern Africa, Northeastern Atlantic, Mediterranean Basin and Middle East from direct-sun AERONET observations. Atmos. Chem. Phys. 2009, 9, 8265-8282. [CrossRef]

31. Perrone, M.R.; Romano, S.; Orza, J.A.G. Particle optical properties at a Central Mediterranean site: Impact of advection routes and local meteorology. Atmos. Res. 2014, 145-146, 152-167. [CrossRef]

32. Burton, N.C.; Grinshpun, S.A.; Reponen, T. Physical collection efficiency of filter materials for bacteria and viruses. Ann. Occup. Hyg. 2007, 51, 143-151. [CrossRef] [PubMed]

33. Perrone, M.R.; Romano, S.; Genga, A.; Paladini, F. Integration of optical and chemical parameters to improve the particulate matter characterization. Atmos. Res. 2018, 205, 93-106. [CrossRef]

34. Lucarelli, F.; Calzolai, G.; Chiari, M.; Giannoni, M.; Mochi, D.; Nava, S.; Carraresi, L. The upgraded external-beam PIXE/PIGE set-up at LABEC for very fast measurements on aerosol samples. Nucl. Instrum. Methods B 2014, 318, 55-59. [CrossRef]

35. Lucarelli, F.; Calzolai, G.; Chiari, M.; Nava, S.; Carraresi, L. Study of atmospheric aerosols by IBA techniques: The LABEC experience. Nucl. Instrum. Methods B 2018, 417, 121-127. [CrossRef] 
36. Visentin, M.; Pagnoni, A.; Sarti, E.; Pietrogrande, M.C. Urban PM2.5 oxidative potential: Importance of chemical species and comparison of two spectrophotometric cell-free assays. Environ. Pollut. 2016, 219, 72-79. [CrossRef]

37. Wang, T.; Cai, G.; Qiu, Y.; Fei, N.; Zhang, M.; Pang, X.; Jia, W.; Cai, S.; Zhao, L. Structural segregation of gut microbiota between colorectal cancer patients and healthy volunteers. ISME J. 2012, 6, 320-329. [CrossRef]

38. Innocente, E.; Squizzato, S.; Visin, F.; Facca, C.; Rampazzo, G.; Bertolini, V.; Gandolfi, I.; Franzetti, A.; Ambrosini, R.; Bestetti, G. Influence of seasonality, air mass origin and particulate matter chemical composition on airborne bacterial community structure in the Po Valley, Italy. Sci. Total Environ. 2017, 593-594, 677-687. [CrossRef]

39. Van den Wollenberg, A.L. Redundancy analysis an alternative for canonical correlation analysis. Psychometrika 1977, 42, 207-219. [CrossRef]

40. Paliy, O.; Shankar, V. Application of multivariate statistical techniques in microbial ecology. Mol. Ecol. 2016, 25, 1032-1057. [CrossRef]

41. Jones, D.L. Fathom Toolbox for MATLAB: Software for Multivariate Ecological and Oceanographic Data Analysis; College of Marine Science, University of South Florida: St. Petersburg, FL, USA, 2017; Available online: https://www.marine.usf.edu/research/matlab-resources/ (accessed on 2 December 2019).

42. Chow, J.C. Measurement Methods to Determine Compliance with Ambient Air Quality Standards for Suspended Particles. J. Air Waste Manag. Assoc. 1995, 45, 320-382. [CrossRef] [PubMed]

43. Amato, F.; Pandolfi, M.; Escrig, A.; Querol, X.; Alastuey, A.; Pey, J.; Perez, N.; Hopke, P.K. Quantifying road dust resuspension in urban environment by Multilinear Engine: A comparison with PMF2. Atmos. Environ. 2009, 43, 2770-2780. [CrossRef]

44. Lyamani, H.; Olmo, F.J.; Alados-Arboledas, L. Physical and optical properties of aerosols over an urban location in Spain: Seasonal and diurnal variability. Atmos. Chem. Phys. 2010, 10, 239-254. [CrossRef]

45. Romano, S.; Di Salvo, M.; Rispoli, G.; Alifano, P.; Perrone, M.R.; Talà, A. Airborne bacteria in the Central Mediterranean: Structure and role of meteorology and air mass transport. Sci. Total Environ. 2019, 697, 134020. [CrossRef]

46. Stein, A.F.; Draxler, R.R.; Rolph, G.D.; Stunder, B.J.B.; Cohen, M.D.; Ngan, F. NOAA's HYSPLIT Atmospheric Transport and Dispersion Modeling System. Bull. Am. Meteorol. Soc. 2015, 96, 2059-2077. [CrossRef]

47. Perrone, M.R.; Vecchi, R.; Romano, S.; Becagli, S.; Traversi, R.; Paladini, F. Weekly cycle assessment of PM mass concentrations and sources, and impacts on temperature and wind speed in Southern Italy. Atmos. Res. 2019, 218, 129-144. [CrossRef]

48. Becagli, S.; Anello, F.; Bommarito, C.; Cassola, F.; Calzolai, G.; Iorio, T.D.; di Sarra, A.; Gómez-Amo, J.-L.; Lucarelli, F.; Marconi, M.; et al. Constraining the ship contribution to the aerosol of the central Mediterranean. Atmos. Chem. Phys. 2017, 17, 2067-2084. [CrossRef]

49. Chirizzi, D.; Cesari, D.; Guascito, M.R.; Dinoi, A.; Giotta, L.; Donateo, A.; Contini, D. Influence of Saharan dust outbreaks and carbon content on oxidative potential of water-soluble fractions of PM2.5 and PM10. Atmos. Environ. 2017, 163, 1-8. [CrossRef]

50. Romano, S.; Perrone, M.R.; Pavese, G.; Esposito, F.; Calvello, M. Optical properties of PM2.5 particles: Results from a monitoring campaign in southeastern Italy. Atmos. Environ. 2019, 203, 35-47. [CrossRef]

51. Calas, A.; Uzu, G.; Martins, J.M.F.; Voisin, D.; Spadini, L.; Lacroix, T.; Jaffrezo, J.-L. The importance of simulated lung fluid (SLF) extractions for a more relevant evaluation of the oxidative potential of particulate matter. Sci. Rep. 2017, 7, 1-12. [CrossRef]

52. Janssen, N.A.H.; Yang, A.; Strak, M.; Steenhof, M.; Hellack, B.; Gerlofs-Nijland, M.E.; Kuhlbusch, T.; Kelly, F.; Harrison, R.; Brunekreef, B.; et al. Oxidative potential of particulate matter collected at sites with different source characteristics. Sci. Total Environ. 2014, 472, 572-581. [CrossRef] [PubMed]

53. Sun, Y.; Xu, S.; Zheng, D.; Li, J.; Tian, H.; Wang, Y. Effects of haze pollution on microbial community changes and correlation with chemical components in atmospheric particulate matter. Sci. Total Environ. 2018, 637-638, 507-516. [CrossRef] [PubMed]

54. Okuda, T.; Kato, J.; Mori, J.; Tenmoku, M.; Suda, Y.; Tanaka, S.; He, K.; Ma, Y.; Yang, F.; Yu, X. Daily concentrations of trace metals in aerosols in Beijing, China, determined by using inductively coupled plasma mass spectrometry equipped with laser ablation analysis, and source identification of aerosols. Sci. Total Environ. 2004, 330, 145-158. [CrossRef] [PubMed] 
55. Gao, J.; Tian, H.; Cheng, K.; Lu, L.; Zheng, M.; Wang, S.; Hao, J.; Wang, K.; Hua, S.; Zhu, C.; et al. The variation of chemical characteristics of PM2.5 and PM10 and formation causes during two haze pollution events in urban Beijing, China. Atmos. Environ. 2015, 107, 1-8. [CrossRef]

56. Perrone, M.R.; Becagli, S.; Garcia Orza, J.A.; Vecchi, R.; Dinoi, A.; Udisti, R.; Cabello, M. The impact of long-range-transport on PM1 and PM2.5 at a Central Mediterranean site. Atmos. Environ. 2013, 71, 176-186. [CrossRef]

(C) 2020 by the authors. Licensee MDPI, Basel, Switzerland. This article is an open access article distributed under the terms and conditions of the Creative Commons Attribution (CC BY) license (http://creativecommons.org/licenses/by/4.0/). 